\title{
Chronic Kidney Disease Stages Are Appropriate at All Ages
}

\author{
Beatrice Goilav Frederick J. Kaskel \\ Division of Pediatric Nephrology, Children's Hospital at Montefiore, Albert Einstein College of Medicine, \\ Bronx, N.Y., USA
}

\section{Key Words}

Chronic kidney disease in children $\cdot \mathrm{K} / \mathrm{DOQ}$ guidelines •

Glomerular filtration rate $\cdot$ Chronic kidney disease

complications

\begin{abstract}
Chronic kidney disease (CKD) is associated with multiple detrimental consequences to the cardiovascular and musculoskeletal systems. The effects of CKD are even more significant when they begin in childhood as they affect growth and (neuro-) development as well. The division into stages of CKD serves as a guideline for the physician to better anticipate and treat early and later manifestations of CKD. For that matter, in adults, the National Kidney Foundation's Kidney Disease Outcomes Quality Initiative has published clinical practice guidelines, which are based on estimated glomerular filtration rate (eGFR). There are no such explicit guidelines published for the pediatric CKD population, mostly (and thankfully) due to its small number. However, given the excellent guidelines published in the adult literature and ongoing clinical work done by dedicated pediatric nephrologists, similar guidelines for children could be extrapolated and determined. As a matter of fact, the pediatric nephrology community is anxiously anticipating the results of the ongoing Chronic Kidney Disease in Children study, which is the first multicenter, prospective, observational pediatric
\end{abstract}

study of such kind. This article summarizes the adequacy of CKD stages at all ages based not only on opinions of experienced clinicians, but also on evidence provided by cross-sectional data analyses of the Chronic Kidney Disease in Children study.

Copyright ๑ 2011 S. Karger AG, Basel

\section{Introduction}

Since the Medieval Ages, we have come a long way in understanding that there are many differences between adults and children [1]. The etiology of chronic kidney disease (CKD) in children is significantly different from that in the adult population as well. This fact has implications when one is evaluating the complications associated with advancing stages of CKD. The matter is further complicated by the heterogeneity of the pediatric population in itself. Based on data from the North American Pediatric Renal Trials and Collaborative Studies (NAPRTCS) registry, most infants with end-stage kidney disease (ESKD) have underlying congenital and urological abnormalities, while most adolescents progress to ESKD due to a glomerular disorder [2]. The latter entity is accompanied by significantly different complications than is the further, such as hypertension (HTN) and proteinuria. Because patients are often asymptomatic before 
ESKD, little epidemiologic information is available on the prevalence of children with earlier stages of CKD. From the US Renal Data System (USRDS), we know the adjusted point prevalence of ESKD among youth younger than 20 in the US was 82 per million population in 2004-2006 [3]. The number of children and adolescents who have less severe kidney disease is likely much higher [4].

Most of the data presented in this article are derived from preliminary cross-sectional data analyses of the enrollees of the Chronic Kidney Disease in Children (CKiD) study. The Kidney Disease Outcomes Quality Initiative (K/DOQI) guidelines employ the Schwartz formula, which utilizes the proportionality between glomerular filtration rate (GFR) and height/serum creatinine to obtain an estimated GFR (eGFR). Mean differences between estimated and measured GFR ranging from 0.4 to 10 $\mathrm{ml} / \mathrm{min} / 1.73 \mathrm{~m}^{2}$ with SD ranging from 2 to $20 \mathrm{ml} / \mathrm{min} /$ $1.73 \mathrm{~m}^{2}$ are reported. The eGFR by Schwartz formula increases with decreasing GFR. In recognition of this caveat, the investigators of the CKiD study utilized iohexol disappearance as a method of measuring GFR (iGFR). Hence, all data presented below will utilize iGFR as a measure of renal function.

\section{Proteinuria}

Proteinuria is not only a marker of kidney damage, but it is also responsible for progressive kidney injury in both adults and children. In an unadjusted linear regression analysis, the investigators of the CKiD study found that the level of proteinuria was associated with iGFR, age, race, and glomerular cause of CKD [5]. For every $10 \%$ decrease in iGFR, urinary protein-to-creatinine ratio $(\mathrm{Up} / \mathrm{c})$ increased on average by $14 \%$. While the magnitude of the association between Up/c and iGFR did not differ by CKD diagnosis, patients with glomerular CKD had Up/c levels on average $140 \%$ greater than those of nonglomerular patients. After adjusting for age, gender, race, BMI, cause of CKD, and RAS antagonist use in the multivariable regression analysis, the relationship between iGFR and $\mathrm{Up} / \mathrm{c}$ remained statistically significant [5].

\section{Hypertension}

Hypertension is a well-described complication of CKD. The prevalence of HTN is approximately $80 \%$ in hemodialysis patients and $50 \%$ in peritoneal dialysis patients [6]. In patients with earlier stages of kidney disease,
HTN is also highly prevalent, but varying with patient characteristics such as the cause of kidney disease [7]. HTN is associated with a greater rate of decline in kidney function and risk of development of ESKD. The relationship between GFR and prevalence of HTN was studied in the baseline cohort of the MDRD Study, and at GFR levels of $60-90 \mathrm{ml} / \mathrm{min} / 1.73 \mathrm{~m}^{2}$ the prevalence of HTN was approximately $65-75 \%$ [8]. HTN is already common in the early stages of CKD, with $48-63 \%$ of children affected [9]. More than $50 \%$ of children on dialysis therapy have uncontrolled HTN, and an additional 20\% have controlled HTN [9-11]. Data from the 2006 NAPRTCS report reveal that $39 \%$ of children enrolled in its CKD registry since its inception were being treated with antihypertensive medications at enrollment [2]. The study also demonstrated that HTN plays a role in progression of CKD in children [11]. The rate of progression of CKD in children with HTN was compared with that in normotensive children. The time to end point was defined as the time between registry enrollment and progression to initiation of renal replacement therapy, or a $10 \mathrm{ml} / \mathrm{min} /$ $1.73 \mathrm{~m}^{2}$ decline in eGFR from baseline, whichever happened first. The rate of CKD progression was significantly greater for those with higher systolic blood pressure (BP), older age, and estimated GFR $<50 \mathrm{ml} / \mathrm{min} / 1.73 \mathrm{~m}^{2}$. Analysis of baseline BP data collected on participants in the CKiD Study yielded significant new information [12]. For systolic BP, 17\% had uncontrolled HTN (BP >95th percentile) and 7\% pre-HTN (BP 90-95th percentile). The overall prevalence of systolic HTN was $53 \%$. For diastolic BP, $16 \%$ had uncontrolled HTN, and $11 \%$ pre-HTN. The overall prevalence of diastolic HTN (controlled and uncontrolled) was $54 \%$. A mean iGFR of $43 \pm 14 \mathrm{ml} /$ $\mathrm{min} / 1.73 \mathrm{~m}^{2}$ was associated with both systolic and diastolic BP $\geq 95$ th percentile.

\section{Anemia}

According to the 2004 USRDS data, the mean eGFR at initiation of renal replacement therapy in children is 10.3 $\mathrm{ml} / \mathrm{min} / 1.73 \mathrm{~m}^{2}$, and at that point $35-40 \%$ of children are on erythropoiesis-stimulating agents (ESAs) [3]. Although there is no clear-cut level of eGFR at which there is an increased risk for the development of anemia, it is suggested that a GFR $<35 \mathrm{ml} / \mathrm{min} / 1.73 \mathrm{~m}^{2}$ represents a stage, at which, despite adequate iron stores, the vast majority of children will need ESA therapy [13]. The CKiD study recently provided some insight into the association of GFR and anemia in children before dialysis [14]. De- 
creasing iGFR, African-American race, glomerular disease as the underlying cause of CKD, current ESA use, and current iron supplement use were associated with decreased $\mathrm{Hb}$ levels. For all children, a $20 \%$ decrease in iGFR was associated with an average decrease in $\mathrm{Hb}$ level of $0.2-0.4 \mathrm{~g} / \mathrm{dl}$.

\section{Cardiovascular Disease}

Functional abnormalities of the vascular endothelium have implicated cardiovascular disease in children with moderate (stage 3-4) CKD and ESKD [15]. The expected remaining lifetime after ESKD in the $0-14$ years age group is 30 years, and the principal cause of death during young adulthood is premature cardiovascular disease [3]. According to the USRDS Annual Report, cardiovascular mortality among pediatric patients with ESKD has been rising, from 17.7 deaths per 1,000 patient-years at risk in 1991 to 23.4 in 2005 [3]. In the registry of the NAPRTCS, $22.8 \%$ of 471 deaths in pediatric dialysis patients were attributed to cardiopulmonary causes [16]. Chavers et al. [17] demonstrated that $31.1 \%$ of incident pediatric dialysis patients aged $0-19$ years experienced a cardiac-related event in up to 7 years of follow-up. Arrhythmias occurred at 91128.6 events per 1,000 patient-years at risk, while cardiomyopathy was reported at rates of $42-85$ events per 1,000 patient-years at risk [17]. Mitsnefes et al. [18] assessed left ventricular mass in 25 children with mild-to-moderate $\mathrm{CKD}$, and found that $22 \%$ of CKD patients had left ventricular hypertrophy (LVH) or developed LVH during a 2 -year follow-up. CKD is associated with a marked prevalence of arterial calcification in both adults and children [19]. Elevated serum levels of calcium and phosphate have been recognized as risk factors for vascular calcification in CKD. In a study of 44 pediatric patients with CKD stages 2-4 and 16 patients with ESKD, an increased calciumphosphorus product predicted increased carotid intima media thickness. Increased serum phosphorus and PTH predicted increased arterial stiffness [20].

\section{Dyslipidemia}

Dyslipidemia is a known risk factor for atherosclerosis and is frequent among both adults and children with CKD [21]. In addition, there is evidence to suggest that dyslipidemia contributes to the initiation and progression of CKD itself [22]. Dyslipidemia occurs early in the progression of CKD (GFR $30-59 \mathrm{ml} / \mathrm{min} / 1.73 \mathrm{~m}^{2}$ ) and increases in prevalence as kidney function deteriorates [22]. Hypertriglyceridemia and hypercholesterolemia have been reported in 90 and $69 \%$ of children with CKD stage 5, respectively [23]. The investigators of the CKiD study recently described the prevalence and pattern of dyslipidemia in children with moderate CKD [24]. Triglyceride levels increase on average by $8 \%$ for every $10 \mathrm{ml} /$ $\mathrm{min} / 1.73 \mathrm{~m}^{2}$ decrease in GFR. A linear relationship was observed between high-density lipoprotein cholesterol (HDL-C) and GFR. Each $10 \mathrm{ml} / \mathrm{min} / 1.73 \mathrm{~m}^{2}$ decrease in GFR was associated with a $3 \%$ decrease in HDL-C. Additionally, for each $10 \mathrm{ml} / \mathrm{min} / 1.73 \mathrm{~m}^{2}$ lower GFR, nonHDL-C was greater. No relationship was observed between total cholesterol and GFR. Lower GFR was more strongly associated with combined dyslipidemia than with overall dyslipidemia. Children with iGFR $<30 \mathrm{ml} /$ $\min / 1.73 \mathrm{~m}^{2}$ were about three times more likely to have any dyslipidemia than children with iGFR $>50 \mathrm{ml} /$ $\min / 1.73 \mathrm{~m}^{2}$, and were eight to nine times more likely to have combined dyslipidemia than children with iGFR $>50 \mathrm{ml} / \mathrm{min} / 1.73 \mathrm{~m}^{2}$ [24].

\section{Growth and Nutrition}

In the general population, the World Health Organization has defined undernutrition as weight-for-age, height-for-age, and weight-for-height $\geq 2$ SDs less than the Centers for Disease Control and Prevention reference median [25]. However, this definition may be inappropriate in children with CKD. Stunting as a definition of undernutrition makes it a poor choice in children with CKD. In this population, anthropometric definitions of undernutrition are complicated [26]. Fat mass is increased relative to height in children with CKD [26]. Children who have congenital CKD typically fall below the third percentile during the first 15 months of life [27]. Growth retardation tends to be proportional to the decrement of GFR [27]. Growth may be impaired even with mild CKD in infants [28]. Therefore, growth parameters should be monitored at least twice as frequently in infants with CKD as is recommended for healthy infants. In older children, the impact of CKD on growth appears to depend to a large degree on the severity of CKD. A 'doseresponse' relationship between GFR and BMI-for-age z score with lower GFR associated with lower mean BMIfor-age $\mathrm{z}$ score was reported [29]. Intestinal calcium absorption is increasingly impaired in those with CKD as endogenous production of calcitriol (1,25-dihydroxyvitamin D) decreases. In one study, $92 \%$ of children had 
25-hydroxy vitamin D deficiency and 36\% had 1,25-dihydroxy vitamin $\mathrm{D}$ deficiency. In children with CKD stage 3 , dietary phosphorus restriction decreases elevated PTH levels and increases 1,25-dihydroxyvitamin D production [30]. In infants, particular attention to potassium levels should be paid, as they physiologically require higher levels to allow cellular growth. It has been shown that renal potassium excretion typically is maintained until GFR decreases to $<10-15 \mathrm{ml} / \mathrm{min} / 1.73 \mathrm{~m}^{2}$.

\section{Neurocognitive Impairment}

Early reports of the cognitive development of infants and children with CKD stages 2-3 revealed findings of profound developmental delay in $60-85 \%$ of infants with severe renal insufficiency, with delays in gross motor and language development being most common [31]. The development of 15 toddlers with CKD who were being conservatively managed was compared with that of 16 children who were on dialysis [32]. Patients with CKD achieved a higher intelligence quotient than those on dialysis. Children with CKD were found to have deficits in verbal abstraction abilities and in visual-motor abilities [33].

\section{Health-Related Quality of Life}

The investigators of the CKiD study reported baseline cross-sectional health-related quality of life (HRQoL) data from their cohort. The median iGFR was $42.5 \mathrm{ml} /$ $\min / 1.73 \mathrm{~m}^{2}$. The HRQoL of these children was poorer than that of healthy children [34]. Both youth with CKD and their parents reported that overall HRQoL as well as physical, social, emotional, and school functioning was poorer than for healthy youth, with worst outcome in school functioning. This report demonstrated that HRQoL was significantly affected early on in the course of CKD. Short stature was also associated with a negative impact on overall QoL and increased the odds of significant impairment in the area of physical functioning [34].

\section{Sleep and Fatigue}

The investigators of the CKiD study evaluated the correlation of CKD severity with symptoms of sleep problems and aspects of fatigue [35]. The participants had a median iGFR of $42.0 \mathrm{ml} / \mathrm{min} / 1.73 \mathrm{~m}^{2}$. Parents of patients with lower iGFRs had higher odds of reporting a greater frequency of low energy than parents of patients with iGFR $>50 \mathrm{ml} / \mathrm{min} / 1.73 \mathrm{~m}^{2}$. Reports of increased weakness and greater severity of falling asleep during the day were more common in those with iGFR $<30 \mathrm{ml} / \mathrm{min} /$ $1.73 \mathrm{~m}^{2}$ than in those with iGFR $>50 \mathrm{ml} / \mathrm{min} / 1.73 \mathrm{~m}^{2}$. Patients with iGFR $<30 \mathrm{ml} / \mathrm{min} / 1.73 \mathrm{~m}^{2}$ were four times more likely to report more severe weakness than patients with iGFR $>50 \mathrm{ml} / \mathrm{min} / 1.73 \mathrm{~m}^{2}$. Patients with iGFR of $40-50 \mathrm{ml} / \mathrm{min} / 1.73 \mathrm{~m}^{2}$ were three times more likely to report more severe problems of falling asleep during the day than patients with iGFR $>50 \mathrm{ml} / \mathrm{min} / 1.73 \mathrm{~m}^{2}$ [35].

\section{Conclusions}

This report provides evidence of correlation of progression to higher CKD stages with the onset of new complications in various age groups of children. Hence, CKD staging is appropriate for all age groups. Granted, the traditional division into CKD stages in the pediatric K/ DOQI guidelines utilized the eGFR by the Schwartz formula, which was shown to overestimate true GFR in advanced CKD stages. Therefore, an argument could be made that what was regarded as moderate CKD, was more likely severe CKD. Nonetheless, the staging of CKD is an invaluable tool to allow the development of guidelines. Thankfully, preliminary data of the CKiD study have shown us that iohexol disappearance is an adequate measurement of GFR. The cross-sectional analysis of CKiD study entry data argues that iohexol disappearance will allow us to clearly correlate the degree of renal dysfunction with occurrence of complications. The correlations are appropriate for objective measurements, such as proteinuria and $\mathrm{BP}$, as well as for measurements as subjective as quality of life of the child. The investigators have also returned to the drawing board to correct GFR calculations to better approximate them to true GFR. Iohexol disappearance is currently not a useful tool in clinical practice, because it requires multiple blood draws. However, the CKiD investigators are developing a more practical clearance method requiring only two blood draws several hours apart, which will allow it to become a clinically feasible measurement. It is clear that the outcome data of the CKiD study will revolutionize the pediatric K/DOQI guidelines in many ways and will provide powerful armamentarium to pediatric nephrologists to better anticipate, pursue, and treat complications of advancing CKD stages and thereby, hopefully, also slow disease progression. 


\section{References}

1 Clifton N: The function of childhood in Amis and Amiloun. Mediaevalia 1998;22: 35-57.

2 North American Pediatric Renal Trials and Collaborative Studies: 2006 Annual Report. Rockville, Emmes Corporation, 2006.

3 US Renal Data System: USRDS 2008 Annual Data Report: Atlas of Chronic Kidney Disease and End-Stage Renal Disease in the United States. Bethesda, National Institutes of Health, National Institute of Diabetes and Digestive and Kidney Diseases, 2007.

4 Warady BA, Chadha V: Chronic kidney disease in children: the global perspective. Pediatr Nephrol 2007;22:1999-2009.

5 Wong CS, Pierce CB, Cole SR, Warady BA, Mak RHK, Benador NM, Kaskel FJ, Furth SL, Schwartz GJ, on behalf of the CKiD investigators: Association of proteinuria with race, cause of chronic kidney disease, and glomerular filtration rate in the Chronic Kidney Disease in Children Study. Clin J Am Soc Nephrol 2009;4:812-819.

-6 Rocco MV, Flanagan MJ, Beaver S, Frederick P, Gentile DI, McClellan WM, Polder J, Prowant BF, Taylor L, Helgersson SD: Report from the 1995 core indicators for peritoneal dialysis study group. Am J Kidney Dis 1997; 30:165-173

-7 National High Blood Pressure Education Program Working Group: 1995 Update of the working group reports on chronic renal failure and renovascular hypertension. Arch Intern Med 1995;156:1938-1947.

-8 Buckalew VM Jr, Berg RL, Wang SR, Porush JG, Rauch S, Schulman G: Prevalence of hypertension in 1,795 subjects with chronic renal disease: the modification of diet in renal disease study baseline cohort. Modification of Diet in Renal Disease Study Group. Am J Kidney Dis 1996;28:811-821.

-9 Hadtstein C, Schaefer F: Hypertension in children with chronic kidney disease: pathophysiology and management. Pediatr Nephrol 2008;23:363-371.

10 Mitsnefes M, Stablein D: Hypertension in pediatric patients on long-term dialysis: a report of the North American Pediatric Renal Transplant Cooperative Study (NAPRTCS). Am J Kidney Dis 2005;45:309-315.

11 Mitsnefes M, Ho PL, McEnery PT: Hypertension and progression of chronic renal insufficiency in children: a report of the North American Pediatric Renal Transplant Cooperative Study (NAPRTCS). J Am Soc Nephrol 2003;14:2618-2622.
12 Flynn JT, Mitsnefes M, Pierce C, Cole SR, Parekh RS, Furth SL, Warady BA for the CKiD Study Group: Blood pressure in children with chronic kidney disease: a report from the Chronic Kidney Disease in Children Study. Hypertension 2008;52:631-637.

13 McGonigle RJ, Boineau FG, Beckman B, Ohene-Frempong K, Lewy JE, Shadduck RK, Fisher JW: Erythropoietin and inhibitors of in vitro erythropoiesis in the development of anemia in children with renal disease. J Lab Clin Med 1985;105:449-458.

14 Atkinson MA, Pierce CB, Zack RM, Barletta GM, Yadin O, Mentser M, Warady BA, Furth SL: Hemoglobin differences by race in children with CKD. Am J Kidney Dis 2010;55: 1009-1017.

15 Hussein G, Bughdady Y, Kandil ME, Bazaraa HM, Taher H: Doppler assessment of brachial artery flow as a measure of endothelial dysfunction in pediatric chronic renal failure. Pediatr Nephrol 2008;23:2025-2030.

16 North American Pediatric Renal Trials and Collaborative Studies (NAPRTCS) 2007 Annual Report.

17 Chavers BM, Li S, Collins AJ, Herzog CA: Cardiovascular disease in pediatric chronic dialysis patients. Kidney Int 2002;62:648653.

18 Mitsnefes MM, Kimball TR, Kartal J, Witt SA, Glascock BJ, Khoury PR, Daniels SR: Progression of left ventricular hypertrophy in children with early chronic kidney disease: 2-year follow-up study. J Pediatr 2006; 149:671-675.

19 Stenvinkel P, Carrero JJ, Axelsson J, Lindholm B, Heimburger O, Massy Z: Emerging biomarkers for evaluating cardiovascular risk in the chronic kidney disease patient: how do new pieces fit into the uremic puzzle? Clin J Am Soc Nephrol 2008;3:505-521.

20 Mitsnefes MM, Kimball TR, Kartal J, Witt SA, Glascock BJ, Khoury PR, Daniels SR: Cardiac and vascular adaptation in pediatric patients with chronic kidney disease: role of calcium-phosphorus metabolism. J Am Soc Nephrol 2005;16:2796-2803.

21 Saland JM, Ginsberg HN: Lipoprotein metabolism in chronic renal insufficiency. $\mathrm{Pe}$ diatr Nephrol 2007;22:1095-1112.

22 Fried LF, Orchard TJ, Kasiske BL: Effect of lipid reduction on the progression of renal disease: a meta-analysis. Kidney Int 2001;59: 260-269.

23 Querfeld U, Salusky IB, Nelson P, Foley J, Fine RN: Hyperlipidemia in pediatric patients undergoing peritoneal dialysis. Pediatr Nephrol 1988;2:447-452.

24 Saland JM, Pierce CB, Mitsnefes MM, Flynn JT, Goebel J, Kupferman JC, Warady BA, Furth SL, on behalf of the CKiD Investigators: Dyslipidemia in children with chronic kidney disease. Kidney Int 2010, Epub ahead of print.
25 Peterson KE, Chen LC: Defining undernutrition for public health purposes in the United States. J Nutr 1990;120:933-942.

26 Rashid R, Neill E, Smith W, King D, Beattle TJ, Murphy A, Ramage IJ, Maxwell H, Ahmed SF: Body composition and nutritional intake in children with chronic kidney disease. Pediatr Nephrol 2006;21:1730-1738.

27 Betts PR, Magrath G: Growth pattern and dietary intake of children with chronic renal insufficiency. BMJ 1974;2:189-193.

28 Kari JA, Gonzalez C, Ledermann SE, Shaw V, Rees L: Outcome and growth of infants with severe chronic renal failure. Kidney Int 2000; 57:1681-1687.

29 Norman LJ, Coleman JE, Macdonald IA, Tomsett AM, Watson AR: Nutrition and growth in relation to severity of renal disease in children. Pediatr Nephrol 2000;15:259265.

30 Portale AA, Booth BE, Halloran BP, Morris RC Jr: Effect of dietary phosphorus on circulating concentrations of 1,25-dihydroxyvitamin $\mathrm{D}$ and immunoreactive parathyroid hormone in children with moderate renal insufficiency. J Clin Invest 1984;73:1580-1589.

31 Rotundo A, Nevins TE, Lipton M, Lockman LA, Mauer SM, Michael AF: Progressive encephalopathy in children with chronic renal insufficiency in infancy. Kidney Int 1982;21: 486-491

32 Hulstijn-Dirkmaat GM, Damhuis IH, Jetten ML, Koster AM, Schroder CH: The cognitive development of pre-school children treated for chronic renal failure. Pediatr Nephrol 1995;9:464-469.

33 Fennell RS, Fennell EB, Carter RL, Mings EL, Klausner AB, Hurst JR: Association between renal function and cognition in childhood chronic renal failure. Pediatr Nephrol 1990;4:16-20.

34 Gerson AC, Wentz A, Abraham AG, Mendley SR, Hooper SR, Butler RW, Gipson DS, Lande MB, Shinnar S, Moxey-Mims MM, Warady BA, Furth SL: Health-related quality of life of children with mild to moderate chronic kidney disease. Pediatrics 2010; 125:e349-e357.

>35 Roumelioti ME, Wentz A, Schneider MF, Gerson AC, Hooper S, Benfield M, Warady BA, Furth SL, Unruh ML: Sleep and fatigue symptoms in children and adolescents with CKD: a cross-sectional analysis from the Chronic Kidney Disease in Children (CKiD) Study. Am J Kidney Dis 2010;55:269-280. 